\title{
Contraceptive use and preferences of young married women in Kerala, India
}

This article was published in the following Dove Press journal: Open Access Journal of Contraception

\section{Jissa Vinoda Thulaseedharan \\ Achutha Menon Center for Health Science Studies (AMCHSS), Sree Chitra Tirunal Institute for Medical Sciences and Technology (SCTIMST), Trivandrum, Kerala, India}

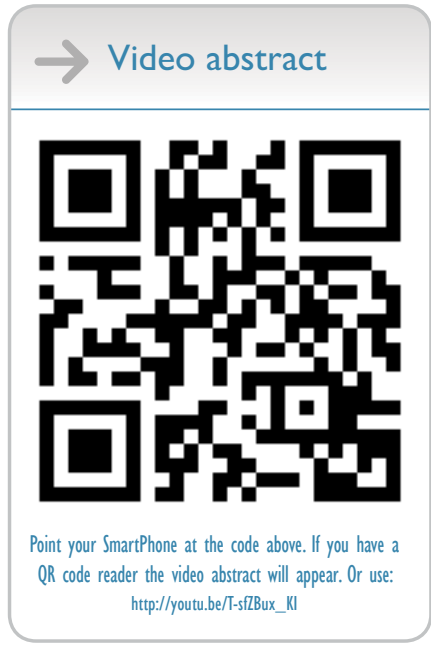

Correspondence: Jissa Vinoda Thulaseedharan

Achutha Menon Center for Health Science Studies (AMCHSS), Sree Chitra Tirunal Institute for Medical Sciences and Technology (SCTIMST), Trivandrum, Medical College PO, Pin 6950II, Kerala, India

Tel +9l 47I 2524270

Email jissa@sctimst.ac.in
Background: As in other states of India, female sterilization is the most widely used contraceptive method in Kerala where women have higher levels of education compared to most other states in India. This paper describes the use and preferences of contraceptive methods among young married women in Trivandrum district, Kerala, India.

Subjects and methods: A community-based cross-sectional survey was carried out among 203 young married women (18-28 years) during January-March 2015 using multistage cluster sampling method. Statistical analysis was mainly descriptive, and chi-squared test was used to test the statistical significance of the relationship between sociodemographic factors and contraceptive use.

Results: The average age at marriage for women was 21.3 years, and $23 \%$ of women had more than one child. Current use of any contraceptive methods was $58 \%$. Female sterilization was preferred by $13 \%$ and it was significantly higher among women aged $25-28$ years than in those aged $18-24$ years $(20 \%$ vs $2.6 \%, p<0.001)$. Female sterilization was significantly lower among women with higher levels of education than in women with an education level of plus two or below $(5.8 \%$ vs $19 \%, p=0.006)$. Women were mostly in favor of female sterilization $(91 \%)$, and a significantly lower proportion of highly educated women preferred female sterilization than women with an education of 12 years or below ( $85 \%$ vs $95.7 \%, p=0.008$ ).

Conclusion: A considerable number of females in the age group 25-28-years opting for sterilization and the unique preference for female sterilization when the family size is complete show the predominant reliance on female sterilization among young women. Higher education delays sterilization in young women due to delayed marriage and childbirth. Women empowerment, proper information and assuring availability and accessibility to different methods can gradually change the dominant preference for female-oriented permanent method of contraception.

Keywords: contraception, female sterilization, Trivandrum, contraceptive preferences

\section{Introduction}

In India, the family planning program was implemented in 1952 as a national population policy to control the rapid growth of population and reduce poverty. ${ }^{1,2}$ Initially, a number of modern methods were focused and later shifted toward male sterilization, but female sterilization became the main focus from late $1970 .^{2}$ The sterilization targets, incentive-based administration, poor standards and forceful nature of the program created negative impression among population and political confrontation in the country. ${ }^{2}$ Until the mid-1990s, almost all reproductive and child health programs focused exclusively on women in India. ${ }^{3}$ In 1998, an informed choice model of service delivery was 
introduced and currently, such a model without any targets or incentives is implemented in the country. ${ }^{2}$ The utilization of contraceptive methods among Indian women is related to several factors such as personal, interpersonal, partner related, service related and/or method related. ${ }^{4}$ The limited choices and access to family planning services, poor quality of available services, cultural and religious opposition, fear of adverse effects and gender-based barriers are responsible for the very high rate of unmet need for contraception in low-resource countries such as India. ${ }^{5}$

Currently, the most common method of contraception in India is female sterilization. ${ }^{4}$ Religion, education and occupation of women were reported to be associated with acceptance of female sterilization. ${ }^{2}$ Lack of information or misinformation regarding temporary methods and less opportunity to prefer modern temporary methods due to affordability and accessibility issues also affect women's choice of female sterilization. ${ }^{6}$ Common misbeliefs such as "vasectomy reduces sexual desire" and "it makes a man physically weak" lead to people's disapproval of vasectomy as a contraceptive method. ${ }^{7,8}$ Even the health workers in India are not well informed about vasectomy, which makes them unable to provide appropriate information regarding vasectomy to motivate people, and therefore, they mainly provide information on female-oriented methods. ${ }^{9}$ One qualitative study among women in low-income communities in Mumbai reported that from the perspective of poor women, the decision to undergo sterilization makes them effectively control their fertility, and hence it leads to improved sexual relationships and emotional health following sterilization. Because of this positive feel, most of them have little poststerilization regret. ${ }^{10}$ All these factors make female sterilization the single choice of contraceptive method for women in countries such as India.

The educational status of women in Kerala is better than in most other states of India, and the enrollment of women in higher education is significantly higher compared to that in other South Indian states. ${ }^{11}$ It is a question of interest whether the higher levels of education influence the contraceptive preferences of young women in Kerala or still tubal occlusion is their single choice of contraception. In this paper, the pattern of contraceptive use among 18-28-year-old married women, their opinions on factors affecting contraceptive use and decision on the number of children, their contraceptive preferences and the reasons to prefer a particular method when family size is complete are described.

\section{Subjects and methods}

This paper is based on a community-based cross-sectional survey carried out in Trivandrum district, Kerala using multistage cluster sampling method. The major objective of the survey was to understand the extent to which young women (18-28 years) are aware of and are able to exercise their reproductive rights. The main target was married women, and the sample size was calculated to be 200 using the assumptions that the anticipated prevalence of any reversible method of contraception among young married women is $15 \%$ in Kerala, ${ }^{12}$ with $95 \%$ CI having an absolute precision of $7 \%$, design effect of 1.5 and refusal rate of $25 \%$.

A summary of the survey and the participating women are given in Figure 1. In order to get a representative sample, five wards (which are the smallest administrative units) from the three administrative areas (corporation, municipality and panchayath) of Trivandrum district were randomly selected and an equal number of participants were decided to be included from each ward. Corporation and municipality cover the urban and semi-urban areas of the district, respectively, and panchayath covers the rural areas of the district. Field investigators selected one point in each ward and visited all houses in one direction to identify married women aged 18-28 years. The field investigator explained the study and purpose of their visit, and sought willingness of the eligible women to participate in the study. A written informed consent was obtained if the woman was willing to participate, and the interview was conducted using a structured interview schedule with open- and closed-ended questions. The process continued till the investigator achieved the target number of subjects from each ward. Field investigator revisited the household by fixing an appointment if the identified woman was not available or was busy with some other things at the time of visit, but wished to participate later in the study. The data collection was completed in 3 months from January to March 2015.

The technical advisory committee and ethics committee of Sree Chitra Tirunal Institute for Medical Sciences and Technology, Trivandrum, approved the study protocol. Participants were informed about the voluntary nature of participation and assured of the privacy and confidentially of the provided information. Each participant was given an individual identification number to distinguish the area (corporation/municipality/panchayath), ward number, household and individual participant. If more than one eligible individual in one household was willing to participate, they were identified with separate individual numbers. 


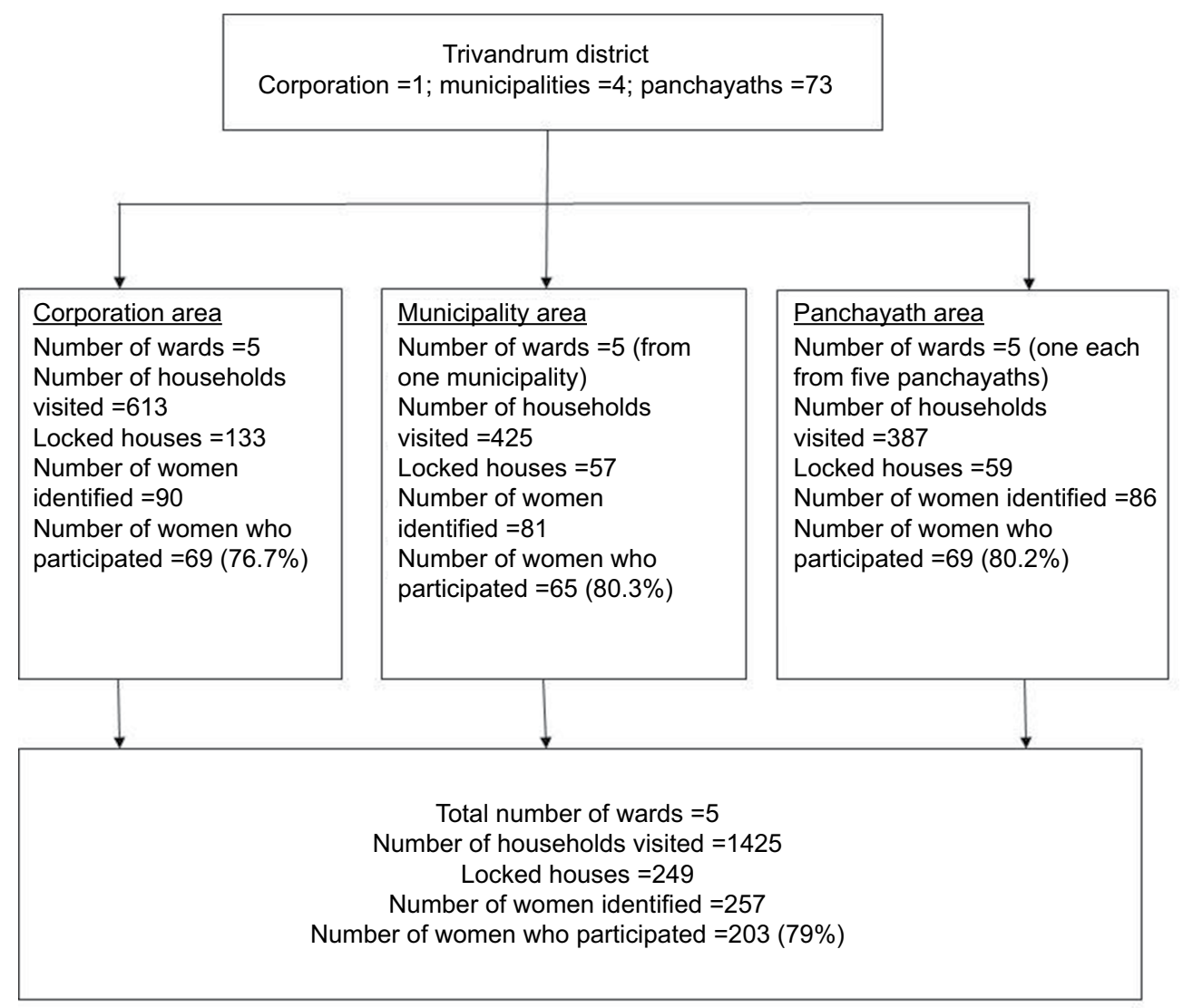

Figure I Summary of the survey and participating women.

However, there were few instances of more than one married woman from the same household participating in the study. Data quality was verified throughout the data collection and data entry process. Data analysis was performed using the statistical software Intercooled STATA 14.1 (STATA/ IC; StataCorp LP, College Station, TX, USA). Statistical analysis was mainly descriptive. The statistical significance of the relationship between sociodemographic factors and contraceptive use was tested using chi-squared test for association. The open-ended question meant to explain the reasons for preferring a particular method when the desired family size was complete was recorded in the provided space in the interview schedule. The survey was conducted in Malayalam and the data entry operator translated the quotes to English and entered them in an Excel sheet. The author verified all translations one by one and did the necessary editing and summarized them.

\section{Results}

The reproductive characteristics of married women are listed in Table 1. The average age at marriage was 21.3 years, and the mean difference of age at marriage and age at first child birth was 1.1 years $(n=157)$. Around $23 \%$ of women
Table I Reproductive characteristics of married women

\begin{tabular}{|c|c|c|}
\hline Characteristics & Mean (SD) & Range \\
\hline Age at marriage $(n=203)$ & $21.3(2.3)$ & $16-28$ \\
\hline Age at first child birth $(n=157)$ & $22.4(2.24)$ & $17-27$ \\
\hline $\begin{array}{l}\text { Age at most recent birth (if more than one } \\
\text { child; } n=47 \text { ) }\end{array}$ & $24.6(1.67)$ & $20-27$ \\
\hline Characteristics & Frequency & $\%$ \\
\hline \multicolumn{3}{|l|}{ Number of children } \\
\hline One & 110 & 54.2 \\
\hline Two & 41 & 20.2 \\
\hline More than two & 6 & 3.0 \\
\hline None & 46 & 22.7 \\
\hline Women currently pregnant* & 32 & 15.8 \\
\hline \multicolumn{3}{|l|}{$\begin{array}{l}\text { Women's opinion on ideal age difference } \\
\text { between two children }(n=203)\end{array}$} \\
\hline$\leq 2$ years & 16 & 7.9 \\
\hline $3-5$ years & 176 & 86.7 \\
\hline$>5$ years & 11 & 5.4 \\
\hline \multicolumn{3}{|l|}{$\begin{array}{l}\text { Comfortable with the gap between childbirths } \\
(n=47)\end{array}$} \\
\hline Emotionally comfortable & 42 & 89.4 \\
\hline Physically comfortable & 43 & 93.5 \\
\hline Physically and emotionally comfortable & 40 & 85.1 \\
\hline $\begin{array}{l}\text { Either physically or emotionally } \\
\text { uncomfortable or physically and emotionally } \\
\text { uncomfortable }\end{array}$ & 7 & 14.9 \\
\hline
\end{tabular}

Note: *Twenty-three women who had no children, seven women who had one child, and two women who had two children were pregnant at the time of interview. 
had more than one child, and the difference in the average age at first child birth and most recent child birth was only 2.2 years $(n=47)$. Only $11.3 \%(n=23)$ of $18-28$-year-old married women were neither pregnant nor having a single child. Majority of women reported that the ideal age difference between two children was 3-5 years, and $85 \%$ of women who had more than one child were physically and emotionally comfortable with the gap between their two deliveries.

The current use of different contraceptive methods is shown in Figure 2. Overall, 118 women were currently using any type of contraceptive method (58\%), of which 27 women had opted for female sterilization. Withdrawal method was the most used method, followed by male condoms. Intrauterine device (IUD) was used by only $2 \%$ of women and no other modern methods were reported by women. Totally, 85 women were currently not using any contraceptive methods, but half of them were pregnant or had recently delivered (Table 2). The main reason for using only traditional methods is "no interest to use other methods" or "fear of side effects". Around $84 \%$ of women had ever used any method of contraception (Figure 3 ), in which male condoms was the predominantly used reversible method (52\%).
The opinions of women on factors that can influence the use of contraceptive methods and the number of children are described in Table 3. Perception regarding the safety of the method was reported to be an important factor that determines the contraceptive use, along with the decision of women as well as their husbands. Women were mostly conscious about their own health and financial status to decide on the number of children they need to have. Ten percent of women reported that the decision on number of children was influenced by family pressure, and $16 \%$ reported that the desire for a son or daughter also would affect the decision on number of children. Women were also asked about the method they would prefer to use when their family size is complete. The responses on preferred methods and the reasons for preferring a certain method are given in Table 4. More than $90 \%$ of women reported that they would prefer tubal occlusion when their family size is complete. Only four women reported that they would prefer vasectomy.

The sociodemographic characteristics of married young women in relation to their current contraceptive use and the preference for female sterilization are described in Table 5. Though the overall prevalence of female sterilization was $13.3 \%$, it was significantly higher among women aged $25-28$

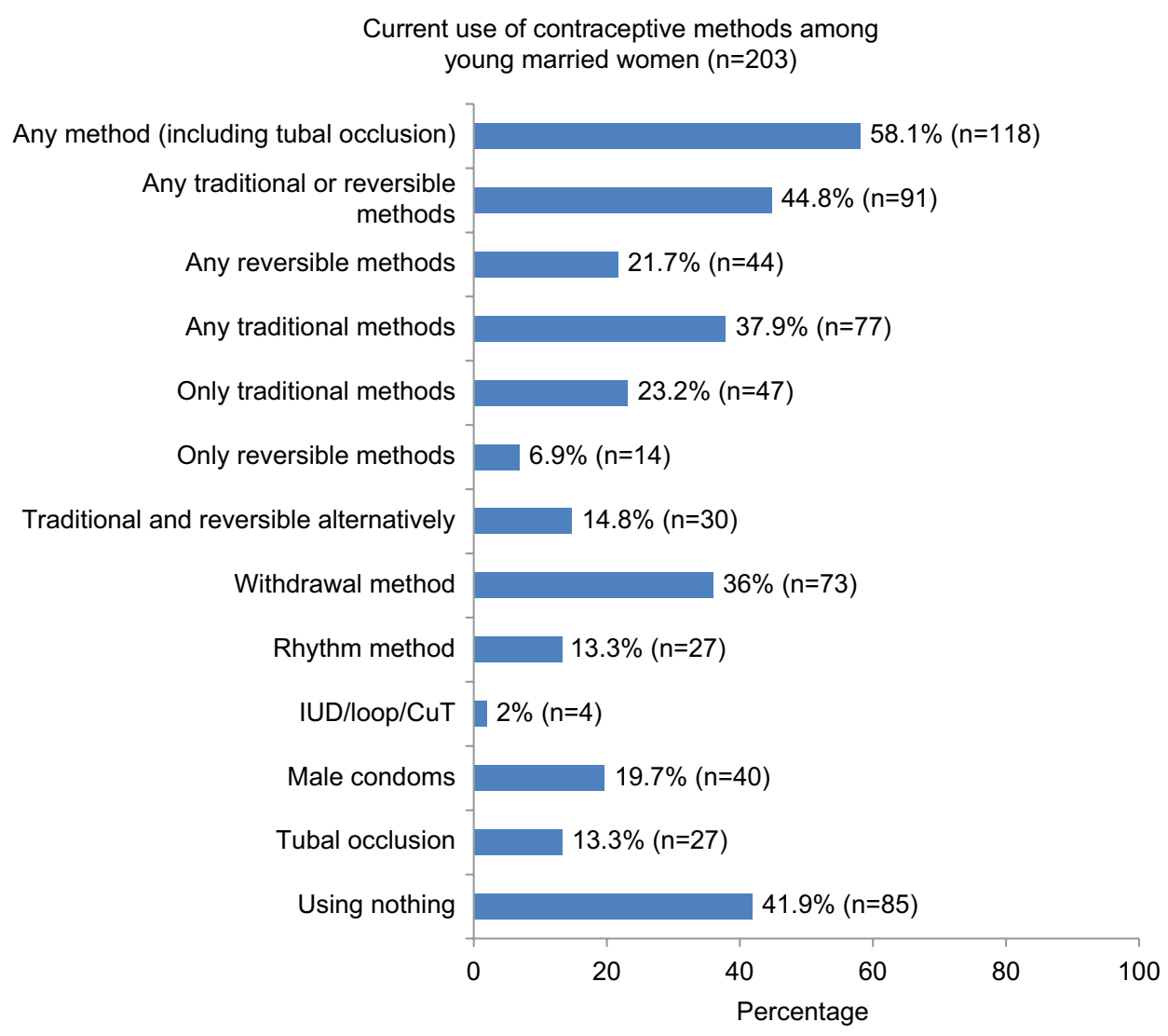

Figure 2 Current use of contraceptive methods among 18-28-year-old married women in Trivandrum. Abbreviations: CuT, copper T; IUD, intrauterine device. 
Table 2 Reasons for current nonuse of contraceptive methods

\begin{tabular}{|c|c|c|c|c|}
\hline \multirow[t]{2}{*}{ Reasons } & \multicolumn{2}{|c|}{$\begin{array}{l}\text { For not using any } \\
\text { contraceptive method }(n=85)\end{array}$} & \multicolumn{2}{|c|}{$\begin{array}{l}\text { For using only traditional method (not } \\
\text { using any reversible method; } n=47 \text { ) }\end{array}$} \\
\hline & Frequency* & $\%$ & Frequency & $\%$ \\
\hline Trying to become pregnant & 20 & 23.5 & & \\
\hline Husband's disapproval & 2 & 2.4 & & \\
\hline Not aware of how to use it & 1 & 1.2 & & \\
\hline Now pregnant/recently delivered & 44 & 51.8 & 3 & 6.4 \\
\hline Husband is abroad/sexual relation is rare & 15 & 17.7 & 1 & 2.1 \\
\hline No interest/fear of side effects & 26 & 30.6 & 43 & 91.5 \\
\hline
\end{tabular}

Note: *Multiple answers were possible.

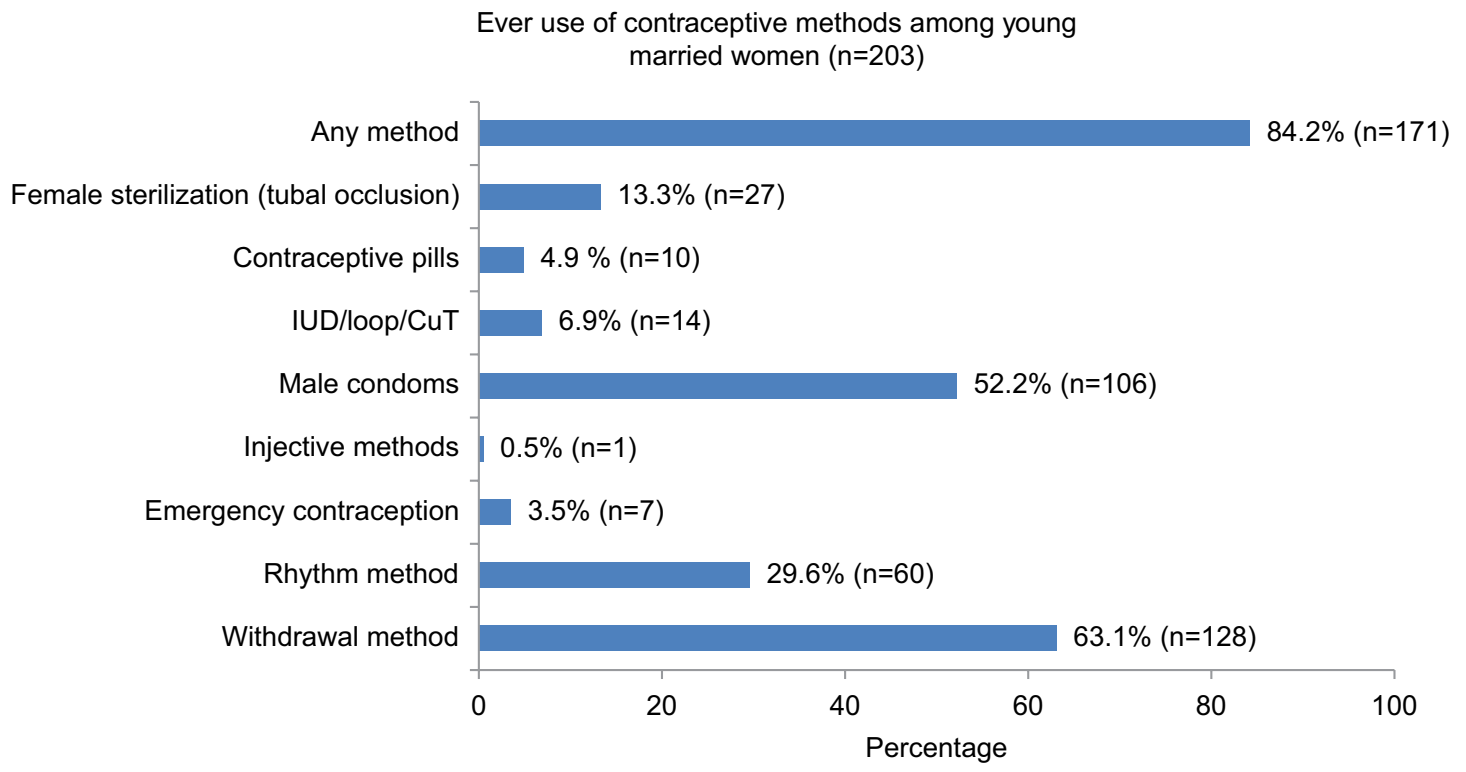

Figure 3 Ever use of contraceptive methods among 18-28-year-old married women in Trivandrum.

Abbreviations: CuT, copper T; IUD, intrauterine device.

Table 3 Factors affecting contraceptive use and decision on number of children - opinions of married women

\begin{tabular}{|c|c|c|}
\hline Questions asked & Frequency* & $\%$ \\
\hline \multicolumn{3}{|c|}{$\begin{array}{l}\text { In your opinion, what are the determinants of your } \\
\text { contraceptive use? }\end{array}$} \\
\hline Own decision & 203 & 100.0 \\
\hline Husband's decision & 203 & 100.0 \\
\hline Perception regarding safety of the method & 198 & 97.5 \\
\hline Recommended by doctor & 91 & 44.8 \\
\hline Advertisements & 34 & 16.8 \\
\hline In laws' approval & 5 & 2.5 \\
\hline Religious belief & 3 & 1.5 \\
\hline Approval by friends & I & 0.5 \\
\hline \multicolumn{3}{|c|}{$\begin{array}{l}\text { What are the factors affecting your decision on number of } \\
\text { children? }\end{array}$} \\
\hline Own health & 136 & 67.0 \\
\hline Financial status & 113 & 55.7 \\
\hline Desire for a son or daughter & 33 & 16.3 \\
\hline Familial pressure & 21 & 10.3 \\
\hline $\begin{array}{l}\text { Ease of accessibility of family planning } \\
\text { services }\end{array}$ & 21 & 10.3 \\
\hline Social norms & 3 & 1.5 \\
\hline
\end{tabular}

Note: *Multiple answers are possible. years than those aged $18-24$ years ( $20 \%$ vs $2.6 \%, p<0.001)$. A significantly lower prevalence of female sterilization was observed among women with higher levels of education than women with education of 12 years or below 12 years $(5.8 \%$ vs $19 \%, p=0.006)$. The current use of any contraceptive method was also significantly lower among highly educated women compared to women with the education level of 12 years or below 12 years $(49.4 \%$ vs $64.7 \%, p=0.030)$. Preference for tubal occlusion was significantly less among highly educated women than the other group ( $85 \%$ vs $95.7 \%, p=0.008$ ).

\section{Discussion}

The acceptance or denial of contraceptive methods is influenced by individual-, family- and community-level factors. ${ }^{13}$ This study provides valid data on the pattern of use of different contraceptive methods among young married women in Kerala, where the women have a better educational and reproductive health status and have a median age at marriage well above 18 years. ${ }^{12}$ The use of reversible methods was very low 
Table 4 Preferred contraceptive method and reasons for preferring a particular method when the desired family size is complete

\section{Methods preferred by married women $(\mathbf{N}=203)$}

Female sterilization (tubal occlusion), $n=185$ (91\%)

\section{Reasons}

I. Safety and surety $(n=\mid 49,80.5 \%)$

2. It is the most common method/most aware of this method $(n=64,35 \%)$

3. No side effects $(n=26,14.1 \%)$

4. It can be done along with delivery/women can take rest along with delivery/men's work will not get affected $(n=23,12.4 \%)$

5. Does not require follow-up/no need of going and buying each time/can save money ( $\mathrm{n}=2 \mathrm{I}, \mathrm{I} I .4 \%)$

6. Husband is not willing/men will not agree/do not want husband to suffer $(n=12,6.5 \%)$

7. If a woman wants, it is possible to make her able to conceive again by a surgery $(n=4,2.2 \%)$

Male sterilization (vasectomy), n=4 I. "Men need little rest after vasectomy."

2. "Wife has to suffer the delivery pain, husband also need to know such worries. But I don't know what my husband's opinion is. Any way we will take a decision only after getting two children."

3. "I am feared to undergo any operation. So prefer to do vasectomy. I will take a decision only after discussing with my husband."

4. "Females are suffering many things like injection, medicines, and pain at the time of delivery. The males also will understand such things if vasectomy is preferred. It is the best thing a man can do for his wife."

Female or male sterilization, $\mathrm{n}=2(1 \%)$

I. "I have some problems with my backbone, and now under treatment. So, the final decision will be depending on my health."

2. "If my husband is willing, I prefer vasectomy. Otherwise, I will undergo tubectomy."

IUD, $\mathrm{n}=\mathrm{I}(0.5 \%)$

Male condoms, $n=2(1 \%)$

I. "Sterilization is not permitted by our religion. CuT is safer than condom and there is no need to go to buy it regularly."

I. "I don't want to suffer the difficulties while undergoing an operation. Condom is safe. If we use any other methods, we need to consult a doctor."

2. "Condoms will not make any risk; it has less chance of pregnancy."

Natural methods, $n=6(3 \%) \quad$ I. "I have no trust in pills and condoms. Tubectomy is a surgery which cuts a part of our body. My husband is so bothered about my health and hence no interest with tubectomy or CuT."

2. "Pills have future side effects. CuT can make discomfort and infection."

3. "Feared to undergo operation."

4. "Withdrawal method has no side effects and also no need to undergo an operation. Also we are confident to follow this method without becoming pregnant."

5. "Stopping delivery is against our religious beliefs. But all females in my family and husband's family did sterilization. But my husband may not allow me to undergo sterilization. Also he is not interested to use any other methods. So we prefer this."

6. "If anything happens to the current children there is no way to get more children in the future. So, withdrawal method may be the better. After stopping delivery, one had to prefer test tube babies [if a woman needs another baby after female sterilization, she has to undergo an in vitro fertilization (IVF) or the so called "prefer test tube babies', which will be quite expensive and has no surety of success]."

Notes: For female sterilization, the number of women reporting a particular reason and its percentage is given. For other methods, the reasons reported by the women are listed because only a few women preferred those methods. The survey was conducted in Malayalam and the data entry operator translated the quotes to English and entered them in the computer, then the author verified all translations one by one and did the necessary editing and summarized them.

Abbreviation: IUD, intrauterine device.

and many women were using only traditional methods. There was only one choice for the majority of the women when their family size was complete, except the fact that very few women preferred a vasectomy, IUD, condoms or traditional methods. Regarding the determinants of contraceptive use by them, it is encouraging that all women gave importance to their decision along with their husbands' decision. In a study on awareness and determinants of contraceptive use among nursing mothers, it was reported that the final decision on contraceptive method was taken by the husband alone or by elders in most families. ${ }^{14}$

According to the National Family Health Survey-3 (NFHS3), current usages of any contraceptive method and a modern reversible method among 20-24-year-old married young women were $33.0 \%$ and $14.9 \%$, respectively. ${ }^{12}$ The estimates from this study show that the current usages of any contraceptive method and a reversible method among 18-28-year-old women were 58\% (95\% CI: 51.3\%-64.7\%) and $21.7 \%$ (95\% CI: 16\%-27.3\%), respectively. These estimates are high compared to NFHS3 estimates. ${ }^{12}$ In this study, one out of five married women in the age group of 25-28 years opted for female sterilization (20\%), but only $2.6 \%$ of 18-24-year-old married women were sterilized. The proportions observed in this study match with the district level household survey- 4 where the sterilization rate was $4.4 \%$ among 20-24-year-old women and 17.6\% among 25-29-year-old women. ${ }^{15}$ Marriage at early age and delivery in short intervals can lead to acceptance of sterilization at a very young age. ${ }^{2}$ 
Table 5 Sociodemographic characteristics vs current use and preference for contraception

\begin{tabular}{|c|c|c|c|c|c|c|}
\hline \multirow[t]{2}{*}{ Characteristics } & \multicolumn{6}{|c|}{ Current use $^{a}$} \\
\hline & $\begin{array}{l}\text { Number } \\
\text { of married } \\
\text { women } \\
(\mathrm{N}=203)\end{array}$ & $\begin{array}{l}\text { Female } \\
\text { sterilization } \\
(n=27)\end{array}$ & $\begin{array}{l}\text { Any modern } \\
\text { method other } \\
\text { than female } \\
\text { sterilization }(n=44)\end{array}$ & $\begin{array}{l}\text { Any } \\
\text { traditional } \\
\text { method } \\
(n=77)\end{array}$ & $\begin{array}{l}\text { Any method } \\
(n=1 \mid 8)\end{array}$ & $\begin{array}{l}\text { Preferring female } \\
\text { sterilization when } \\
\text { family size is } \\
\text { complete }(n=185)\end{array}$ \\
\hline \multicolumn{7}{|l|}{ Age, years } \\
\hline $18-24, \mathrm{n}$ & 78 & $2(2.6)$ & $16(20.5)$ & $29(37.2)$ & 37 (47.4) & $74(95.0)$ \\
\hline $25-28$ & 125 & $25(20)$ & $28(22.4)$ & $48(38.4)$ & $81(64.8)$ & III (88.8) \\
\hline$p$ value & & $<0.001$ & 0.751 & 0.862 & 0.015 & 0.139 \\
\hline \multicolumn{7}{|l|}{ Religion } \\
\hline Hindu & 123 & $17(13.8)$ & $28(22.8)$ & $45(36.6)$ & $73(59.4)$ & 112 (9I.I) \\
\hline Muslim & 36 & $5(13.9)$ & $7(19.4)$ & $15(4 \mid .7)$ & $22(61.1)$ & $32(88.9)$ \\
\hline Christian & 44 & $5(\mathrm{II} .4)$ & $9(20.5)$ & $17(38.6)$ & $23(52.3)$ & $4 \mid(93.2)$ \\
\hline$p$ value & & 0.913 & 0.891 & 0.853 & 0.661 & 0.79 \\
\hline \multicolumn{7}{|l|}{ Type of ration card } \\
\hline APL & 125 & $15(12)$ & $32(25.6)$ & $48(38.4)$ & $75(60.0)$ & II2 (89.6) \\
\hline BPL & 71 & $10(14.1)$ & $9(12.7)$ & $27(38.0)$ & $38(53.5)$ & $66(93.0)$ \\
\hline Nil & 7 & $2(28.6)$ & $3(42.9)$ & $2(28.6)$ & $5(7 \mid .4)$ & $7(100.0)$ \\
\hline$p$ value & & $0.44 I$ & 0.041 & 0.873 & 0.520 & 0.512 \\
\hline \multicolumn{7}{|l|}{ Main activity } \\
\hline Housewives & $|5|$ & $21(13.9)$ & $29(19.2)$ & $55(36.4)$ & $86(57.0)$ & $142(94.0)$ \\
\hline Others $^{\mathrm{b}}$ & 52 & $6(I 1.5)$ & $15(28.9)$ & $22(42.3)$ & $32(61.5)$ & $43(82.7)$ \\
\hline$p$ value & & 0.664 & 0.146 & 0.451 & 0.563 & 0.013 \\
\hline \multicolumn{7}{|c|}{ Highest educational attainment } \\
\hline 12 years or below & 116 & $22(19.0)$ & $23(19.8)$ & $43(37.1)$ & $75(64.7)$ & III (95.7) \\
\hline Highly educated women & 87 & $5(5.8)$ & $21(24.1)$ & $34(39.1)$ & $43(49.4)$ & $74(85.1)$ \\
\hline$p$ value & & 0.006 & 0.461 & 0.770 & 0.030 & 0.008 \\
\hline
\end{tabular}

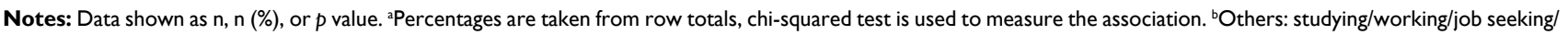
study completed/waiting to join for another course/study stopped/trainee/taking tuition, and so on.

Abbreviations: APL, above poverty line; BPL, below poverty line.

The pattern of contraceptive use in this study was compared with the United Nations Population Division-World Contraceptive Use data for the survey years 2014-2016. ${ }^{16}$ The use of reversible method among 15-49-year-old currently married (or in union) women is above $70 \%$ in Democratic People's Republic of Korea followed by Zimbabwe (65.6\%), whereas in India the prevalence is only $11.8 \%$. This study showed a prevalence of $21.7 \%$ among $18-28$-year-old women, but only $6.9 \%$ were using reversible method alone; the remaining $14.8 \%$ were using reversible and traditional methods alternatively. There are several countries where the prevalence of female sterilization among $15-49$-year-old women is $<5 \%$, whereas India is one among the countries with a high prevalence of female sterilization. Dominican Republic shows the highest prevalence of female sterilization (40.7\%), followed by EI Salvador (37\%), Mexico (36.2\%) and India (36\%). Nepal shows the highest prevalence of vasectomy (4.7\%), whereas in India it is only $0.3 \%$. The use of pills is high in Portugal $(48.3 \%)$ and Zimbabwe (43.9\%), but in India it is only $4.1 \%$. The UN data show that the injective methods are quite popular in Indonesia (36.7\%) and Ethiopia (31.1\%), but are practically nil in India. Though this study population consists of 18-28-year-old women from an Indian state with better socioeconomic posi- tion, the pattern correlates with the overall use of contraceptive methods among 15-49-year-old women in India.

In this study, 92\% (43/47) of women who currently use traditional method alone reported that the reason for not using any reversible method was fear of side effects or no interest, while $31 \%(26 / 85)$ of women who were not using any contraceptive method also reported the same reasons for nonuse of contraception. The data also show that $68 \%$ of women who reported using any reversible methods (30/44) alternatively used traditional methods; thus, the number of women who were using only reversible methods was very low (7\%). Even in an educated society, a large number of young women avoid the use of reversible methods, especially IUDs and injectables which are highly effective, due to fear of side effects, which seeks serious consideration of the health authorities. If the traditional method fails, the women either go for an abortion or will continue with the pregnancy though there is a short interval between the pregnancies. Both can affect the health of young women.

In this study, among women who were currently not using any contraceptive method, $52 \%$ was either pregnant or had recently delivered. Kunwar et al reported that among mothers, a very high prevalence of using condoms $(85.6 \%)$ was 
found within 6 months of postpartum period, but the use was irregular. They also noticed that $74 \%$ of women were sexually active and $54 \%$ had resumed menstruation within 12 weeks postpartum, but the use of contraception at this period was only $36 \% .{ }^{17}$ However, the lack of information on duration of postpartum in the present study precludes looking into the time to initiate contraceptive use after delivery.

Education is an important factor that determines the use of contraception in different ways. In the current study, the low prevalence of contraceptive usage among highly educated women was connected to age at marriage. Women who get married at an early age probably have one or two children before 28 years, and so they need to use either a temporary or a permanent method of contraception; but highly educated women who get married late mostly are trying to conceive, and hence, the current use of any contraceptive method is low among highly educated women in the age group of 18-28 years. A study on determinants of contraceptive use before first pregnancy reported that the contraceptive use was significantly increased if the women had a higher level of education. ${ }^{18}$ Chaurasia did an exploratory study using a multidimensional approach to analyze contraceptive use pattern among different groups of women. In that study, the prevalence of use of permanent methods was decreased and of modern spacing methods was increased with increasing level of wife's education. Also, the prevalence of use of modern spacing method increased with higher levels of living standards. ${ }^{19}$

de Oliveira et al also reported that highly educated and professionally skilled women mostly preferred alternative temporary methods, and relatively higher proportion of Muslim women preferred traditional or modern temporary methods than tubal occlusion in their study. ${ }^{2}$ Chaurasia also reported that Muslim women showed some type of stigma against permanent methods of contraception. Also, the prevalences of use of modern spacing methods and traditional methods were high among Muslim women who had an average standard of living. ${ }^{19}$ But in the present study, I did not find any significant difference in the use of contraceptive methods or in preferring tubal occlusion with respect to women from different religious groups. However, there were three women who reported that religious belief can influence contraceptive use. One woman who preferred IUD and other women who preferred traditional methods when their family size was complete reported that stopping delivery is not permitted or it is against their religious belief.

In this study, more than $90 \%$ of women preferred tubal occlusion when their family size was complete. The most reported reason for preference to tubal occlusion was the perception of its safety, surety and its acceptability in the society. Largely, socioeconomic status determines the persistent dominance of tubal occlusion. ${ }^{2}$ But since the majority of women preferred tubal occlusion, it is difficult to establish such a relation in this study. However, the importance of education is clearly shown by the data where the preference for female sterilization among highly educated women was $10 \%$ less compared to women who had low levels of education. The relationship between preference for tubal occlusion and the occupational status of women also showed the impact of education because the "others" consists of women who were studying/working/job seeking/study completed/waiting to join for another course/study stopped/trainee/taking tuition.

Arora et al reported the reasons for young rural women opting for female sterilization in India. The study highlights that lack of information and/or misinformation about temporary contraception leads to major reliance on female sterilization without thinking about its complications and future regret. ${ }^{6}$ In addition, the vigorous promotion of female sterilization often made it the single choice of contraceptive method in women's reproductive life. ${ }^{2}$ The choice of sterilization is common among poor and socially disadvantaged women. Modern contraceptives including sterilization are freely available in the public sector, and women who access the public sectors for sterilization can avail it free of cost. ${ }^{2}$ In the present study also, many women reported that they prefer female sterilization since there is no need of going and buying it each time and it can save money as it is a single time procedure. NFHS3 data showed that majority of women who accepted tubal occlusion never used any contraceptive method before accepting it. ${ }^{20}$ It was observed from this study that, among women who accepted female sterilization, $70 \%$ $(19 / 23)$ ever used withdrawal method, 52\% (14/23) ever used male condoms and 19\% (5/23) of women ever used IUD, and the ever usage of other methods was much less among those who had done female sterilization.

In this study, participants were recruited from all three administrative areas of Trivandrum district based on random sampling, so that I had a representative sample of young married women in Trivandrum district. Due to the differences in socioeconomic position of women, and availability and accessibility of contraceptive services in different states, these estimates are not generalizable for the young women in India. However, the study provides valid estimates for the contraceptive usage of young married women in Trivandrum district, which may be true for the other districts in Kerala state too. 
Another thing to be noted is the bias in the observed significantly low prevalence of female sterilization among highly educated young women. The low prevalence of sterilization among highly educated young women may not be due to their decision to avoid sterilization and to choose some alternatives, but due to the delayed marriage and pregnancy. Most of them are waiting for their first baby or still waiting to complete their family size and, hence, do not opt for sterilization before the age of 28. However, the observation cannot be ignored just as a biased result because education indirectly made a difference in the proportion of women who underwent female sterilization under the age of 28 years, which has some positive implication. Also, the proportion of women who reported that they would prefer alternative methods other than female sterilization when their family size is complete was higher among highly educated women than women with a lower level of education. Education makes them think about alternative methods, but how many of those women who wish to choose other methods can choose that method in future is a question, because most often, the final decision will be influenced by the opinions of husband and family members. However, taken as a whole, education shows its impact on the current use of contraception and women's preferences.

A considerable number of 25-28-year-old married women opting for female sterilization and the unique preference for female sterilization when the family size is complete show the predominant reliance of young women on female sterilization. It shows the lack of proper information on vasectomy and reversible methods and lack of motivation to use reversible methods to avoid post-sterilization regret since they are at a very young age. Not only the lack of information and motivation, but also the economic implications should be taken into account to promote the use of reversible methods among young women. Women empowerment through educational attainment and proper information on the available contraceptive methods can gradually change the dominance of preference for female-oriented permanent method of contraception.

\section{Acknowledgments}

Ford Foundation is greatly acknowledged for their financial support to conduct this survey as a small activity of the larger project, "Research initiative on factors influencing women's reproductive choices". Professor Sundari Ravindran is acknowledged for her generous support in planning and conduct of the study. The sincere efforts of the field investigators, Ms Geethu and Mrs Anupama, and the data entry operator, Mr Prejith Chandran are acknowledged.

\section{Disclosure}

The author reports no conflicts of interest in this work.

\section{References}

1. Bhuyan K, Ali I, Barua SJ. Role of no scalpel vasectomy in male sterilization. Indian J Surg. 2012;74(4):284-287.

2. de Oliveira IT, Dias JG, Padmadas SS. Dominance of sterilization and alternative choices of contraception in India: an appraisal of the socioeconomic impact. PLoS One. 2014;9(1):e86654.

3. Singh A, Ram F. Men's involvement during pregnancy and childbirth: evidence from rural Ahmadnagar, India. Popul Rev. 2009;48(1):83-102.

4. Jain R, Muralidhar S. Contraceptive methods: needs, options and utilization. J Obstet Gynaecol India. 2011;61(6):626-634.

5. Joshi R, Khadilkar S, Patel M. Global trends in use of long-acting reversible and permanent methods of contraception: seeking a balance. Int J Gynaecol Obstet. 2015;131(1):S60-S63.

6. Arora N, Choudhary S, Raghunandan C. Young women opting for tubal sterilization in rural India: reasons and implications. J Obstet Gynaeco. 2010;30(2):175-178.

7. Perry B, Packer C, Chin Quee D, Zan T, Dulli L, Shattuck D. Recent experience and lessons learned in vasectomy programming in lowresource settings: a document review; 2016. The Population Council, The Evidence Project. Durham, NC: FHI 360 and Washington, DC.

8. Madhukumar S, Pavithra MB. A study about perceptions, attitude, and knowledge among men toward vasectomy in Bangalore rural population. Int J Med Sci Public Health. 2015;4(8):1066-1070.

9. Mahapatra S, Narula C, Thakur CP, Kalita TJ, Mehra R. Assessment of knowledge and perception regarding male sterilization (Non-Scalpel Vasectomy) among community health workers in Jharkhand, India. Indian J Comm Health. 2014;26(4):428-433.

10. Brault MA, Schensul SL, Singh R, Verma RK. Multilevel perspectives on female sterilization in low-income communities in Mumbai, India. Qual Health Res. 2016;26(11):1550-1560.

11. Rasheeja TK, Krishnan C. Empowering women through higher education: the Kerala Episode. Issues Ideas Educ. 2013;1(2):221-229.

12. Santhya KG, Jejeebhoy SJ. The sexual and reproductive health and rights of young people in India: a review of the situation. New Delhi: Population Council; 2012. Available from: http://www.popcouncil. org/uploads/pdfs/2012PGY_IndiaYouthSRHandRights.pdf. Accessed on January 15, 2015.

13. Pandey SM. Correlates of modern contraception practices among married couples in rural area of Hisar (Haryana). Indian J Prev Soc Med. 2011;42(3):274-277.

14. Rao BS, Mathada VC. Awareness and determinants of contraceptive use among nursing mothers in Bellary, Karnataka. J Clin Diagn Res. 2016;10(1):QC15-QC19.

15. International Institute for Population Sciences, District level household and facility survey- 4, 2012-13, Ministry of health and family welfare, Available from: http://rchiips.org/pdf/dlhs4/report/KE.pdf. Accessed January 1, 2017.

16. United Nations, Department of Economic and Social Affairs, Population Division; 2017. World Contraceptive Use; 2017. Available from: http:// www.un.org/en/development/desa/population/publications/dataset/ contraception/wcu2017.shtml. Accessed November 1, 2017.

17. Kunwar S, Faridi MM, Singh S, Zahra F, Alizaidi Z. Pattern and determinants of breast feeding and contraceptive practices among mothers within six months postpartum. Biosci Trends. 2010;4(4):186-189.

18. Pandey A, Singh KK. Contraceptive use before first pregnancy by women in India (2005-2006): determinants and differentials. BMC Public Health. 2015;15:1316.

19. Chaurasia AR. Contraceptive use in India: a data mining approach. Int J Popul Res. 2014; Article ID 821436.

20. International Institute for Population Sciences (IIPS) and Macro International. National Family Health Survey (NFHS-3), India, 2005-2006. Kerala. Mumbai: IIPS; 2008. 


\section{Publish your work in this journal}

Open Access Journal of Contraception is an international, peerreviewed, open access, online journal, publishing original research, reports, reviews and commentaries on all areas of contraception. In addition to clinical research, demographics and health-related aspects, the journal welcomes new findings in animal and preclinical studies relating to understanding the biological mechanisms and practical development of new contraceptive agents. The manuscript management system is completely online and includes a very quick and fair peer-review system. Visit http://www.dovepress.com/testimonials.php to read real quotes from published authors.

Submit your manuscript here: https://www.dovepress.com/open-access-journal-of-contraception-journal 